Using Pearson Chi Square test to evaluate the correlation between children with monosensitisation and polysansitisation with the degree of control asthma we have obtained a $\mathrm{p}$ value $>0.05$, statistically insignificant.

Using Pearson Chi Square test to evaluate the correlation between children with $<2$ exacerbations and $\geq 2$ exacerbations with mono and polysensitisation in children with allergic asthma we have obtained a p value $>0.05$, statistically insignificant.

Conclusion In this study of children with atopic asthma, mono and polysensitisation does not influence the degree control and also hasn't influenced the asthma exacerbations during one year.

\section{P14 EGGSTRA SPECIAL TREATMENT: IN HOSPITAL FOOD CHALLENGES FOR EGG ALLERGY: ARE WE DOING TOO MANY?}

1,2 Miriam Smyth* ${ }^{*}$ Jack McCaffery ${ }^{3}$, John Fitzsimons ${ }^{3}$. 'Our Lady of Lourdes Hospital, Drogheda, Ireland; ${ }^{2} R C S I$, Dublin, Ireland; ${ }^{3}$ Our Lady of Lourdes Hospital Drogheda, Drogheda, Ireland

\subsection{6/archdischild-2019-epa.370}

Aim To assess compliance of our paediatric department with internationally recommended standards for the assessment and management of egg allergy.

Methods Written records of all egg challenges performed in a paediatric assessment unit were collected from 2013-2018. We divided reactive symptoms into three categories; GI, respiratory (mild wheeze) and mucocutaneous involvement. We compared the reactions in children with pre-existing risk factors to those without. The British Society for Allergy and Clinical Immunology (BSACI) recommends that children with mild egg reactions have incremental forms of egg at home. They recommend in-hospital food challenges are reserved for children with co-existing asthma or previous anaphylaxis. We compared our practice with their 2010 egg allergy management guidelines.

Results There were 161 challenges over five years. 92\% of those challenged passed $(n=149) .27 .9 \% \quad(n=45)$ had no reaction. 42 charts were available for more detailed assessment.

In the charts reviewed 47\% $(n=20)$ had asthma and $57 \%$ $(n=24)$ had previous history of anaphylaxis. Of those with asthma, 73.6\% $(n=14)$ passed the challenge and 26\% $(n=5)$ failed and developed anaphylactic symptoms. The median age of those who failed in this asthma cohort was 9.4yrs and $10.7 \mathrm{yrs}$ in those that passed. One patient developed all three symptoms, and 9 developed two symptoms. In the non-asthma cohort $(n=22)$ two patients developed all three, 11 had two symptoms, six patients had one symptom.

Of the 24 children with an anaphylaxis history $79 \%$ $(n=19)$ passed the challenge and 20.8\% $(n=5)$ failed - all of whom also had asthma. Older patients were more likely to pass - median age 11 vs 9.7 yrs.

Conclusion The natural course of egg allergy is to diminish with age. This combined with the BSACI recommendation that clinical diagnosis is sufficient for most children who are not high-risk, removes the need for in-hospital food challenges. Our results show older children were more likely to pass reinforcing the predictability of the natural history. We also showed that even in the 'at risk' group a high percentage were passing and their reactions weren't significantly worse than those without asthma. We currently do not implement BSACI guidelines. This is expensive and may preclude true high-risk candidates from specialist assessment. This study raises some questions: Could children with mild asthma be observed reintroducing baked egg rather than going through a formal challenge? Is it possible to predict the who is going to react from risk factors?

\section{P15 FORMATION OF FOOD ALLERGIES IN CHILDREN BORN TO MOTHERS WITH BRONCHIAL ASTHMA}

${ }^{1}$ Elena Boitsova, ${ }^{1}$ Tamara Kosenkova, ${ }^{2}$ Natalia Bogdanova, ${ }^{2,3}$ Valeria Novikova*, ${ }^{3}$ Olga Lavrova. 'V.A.Almazov National Medical Research Center, St. Petersburg, Russian Federation; ${ }^{2}$ St. Petersburg State Pediatric Medical University, St. Petersburg, Russian Federation; ${ }^{3}$ St. Petersburg First Medical University, St. Petersburg, Russian Federation

\subsection{6/archdischild-2019-epa.371}

Introduction Infants with at least one biological parent who has allergic conditions are at risk for developing allergic disease. Caesarean born infants have a more slowly diversifying microbiota, with differences reported from normally born infants.This, in turn, can affect immunophysiological development with a heightened allergic disease risk.

The aim of this study was to investigate the impact of birth mode of delivery on childhood asthma and allergic diseases in children from mothers with moderate persistent asthma.

The study included 68 mother-child pairs. 22 children (main group) were born by Caesarean section, and 46 children (comparison group) were delivered vaginally. Pregnant women were included in the study with a gestation period of 32-38 weeks. Children were observed in the maternity hospital (1, 3-4 days), then monthly until the age of 1 year with a clinical assessment of the child's health. The presence, age of onset of symptoms, severity (prevalence) of skin (atopic dermatitis, urticaria, angioedema) and respiratory manifestations of allergy (rhinitis, wheezing with or without Viral Upper respiratory infection; croup; chronic cough). Mathematical-statistical data processing was carried out using the program Statistica 10.0 for Windows-10. The criterion for statistical significance was $\mathrm{p}<0.05$.

Results In the group of children born by caesarean section, severe regurgitation was significantly more frequent $(53 \%$ and $29 \%, \mathrm{p}<0.05)$, flatulence persisting for up to 6 months $(82 \%$ and $68 \%, \mathrm{p}<0.05)$, colic lasting longer than 3 hours (93\% and 28\%, p <0.05), dyschezia $(59 \%$ and $33 \%$, p <0.05), loose stools $(86 \%$ and $57 \%$, p <0.05), mucus in the stool $(100 \%$ and $73 \%, \mathrm{p}<0.05)$, appeared in $1-2$ weeks of life $(68 \%$ and $45 \%, \mathrm{p}<0.05)$, skin manifestations of allergy $(95 \%$ and $74 \%, \mathrm{p}<0.05)$, incl. diffuse $(76 \%$ and $53 \%, \mathrm{p}<0.05)$, chronic cough $(18 \%$ and $2 \%, \mathrm{p}$ $<0.05)$, the presence of the first episode of weezing at $4-5$ months $(71 \%$ and $53 \%, p<0.05), 2$ episodes of weezing in the first year of life $(86 \%$ and $20 \%, \mathrm{p}<0.05)$, the presence of croup at the age of 3-6 months $(80 \%$ and $0 \%, p$ $<0.05), 2$ episodes of croup in the first year of life $(40 \%$ and $14 \%, \mathrm{p}<0.05)$.

Conclusion For children with a positive family history of atopic diseases caesarean section can be assumed as an epigenetic factor, contributing to an earlier and pronounced manifestation of not only gastrointestinal, but skin and respiratory symptoms of allergic disease. 